\title{
Prevalence, risk factors and outcomes of patients coming from the community with sepsis due to multidrug resistant bacteria
}

\author{
Nicolò Capsoni ${ }^{1}$, Pietro Bellone', Stefano Aliberti ${ }^{2,3^{*}}$ (D), Giovanni Sotgiu ${ }^{4}$, Donatella Pavanello ${ }^{5}$, Benedetto Visintin ${ }^{6}$, \\ Elena Callisto ${ }^{1}$, Laura Saderi ${ }^{4}$, Davide Soldini ${ }^{6}$, Luca Lardera ${ }^{6}$, Valter Monzani ${ }^{6}$ and Anna Maria Brambilla ${ }^{1}$
}

\begin{abstract}
Background: Although previous studies showed an increasing prevalence of infections due to multi-drug resistant (MDR) bacteria in the community, specific data on sepsis are lacking. We aimed to assess prevalence, risk factors and outcomes of patients with sepsis due to MDR bacteria.

Methods: An observational, retrospective study was conducted on consecutive adult patients coming from the community and admitted to the Policlinico Hospital, Milan, Italy, with a diagnosis of sepsis between January 2011 and December 2015. Primary study outcome was in-hospital mortality.

Results: Among 518 patients, at least one MDR bacteria was isolated in 88 (17\%). ESBL+ Enterobacteriaceae were the most prevalent MDR bacteria (9.7\%) followed by MRSA (3.9\%). Independent risk factors for sepsis due to MDR bacteria were septic shock (OR: 2.2; $p=0.002$ ) and hospitalization in the previous 90 days (OR: $2.3 ; p=0.003)$. Independent risk factors for sepsis due to ESBL+ bacteria were hospitalization in the previous 90 days (OR: $2.1 ; p=0.02$ ) and stroke (OR: $2.1 ; p=0.04)$. A significantly higher mortality was detected among patients with vs. without MDR bacteria (40.2\% vs. $23.1 \%$ respectively, $p=0.001)$. Independent risk factors for mortality among patients with sepsis were coagulation dysfunction (OR: 3.2; $p=0.03$ ), septic shock (OR: 3.2; $p=0.003$ ), and isolation of a MDR bacteria (OR: $4.6 ; p<0.001$ ).

Conclusion: In light of the prevalence and impact of MDR bacteria causing sepsis in patients coming from the community, physicians should consider ESBL coverage when starting an empiric antibiotic therapy in patients with specific risk factors, especially in the presence of septic shock.
\end{abstract}

Keywords: Septic shock, Pneumonia, MRSA, Pseudomonas, ESBL producer Enterobacteriaceae

\section{Summary}

Specific risk factors for MDR bacteria and EBSL+ Enterobacteriaceae are found in a population of 518 patients with sepsis coming from the community. Isolation of a MDR bacteria is associated with higher mortality rates and is an independent risk factor for mortality.

\footnotetext{
* Correspondence: stefano.aliberti@unimi.it

${ }^{2}$ Fondazione IRCCS Ca' Granda Ospedale Maggiore Policlinico, Respiratory Unit and Cystic Fibrosis Adult Center, Via Francesco Sforza 35, 20122 Milan, Italy

${ }^{3}$ Department of Pathophysiology and Transplantation, University of Milan, Milan, Italy

Full list of author information is available at the end of the article
}

\section{Introduction}

Sepsis is a major health-care problem which affects millions of people each year worldwide with an increasing incidence over the last decades [1]. More than one third of patients with sepsis die during their hospital stay and the economic impact of sepsis is relevant, with a mean and median hospital and intensive care unit (ICU) cost of $\$ 32,421$ and $\$ 27,461$ per single patient, respectively $[2,3]$. Recently, a new definition of sepsis and an update of the Surviving Sepsis Campaign guidelines have been published to improve sepsis diagnosis, to standardize communication between clinicians and researchers, and to spread an evidence based approach for the management of septic patients $[1,4]$.

(C) The Author(s). 2019 Open Access This article is distributed under the terms of the Creative Commons Attribution 4.0 International License (http://creativecommons.org/licenses/by/4.0/), which permits unrestricted use, distribution, and reproduction in any medium, provided you give appropriate credit to the original author(s) and the source, provide a link to the Creative Commons license, and indicate if changes were made. The Creative Commons Public Domain Dedication waiver (http://creativecommons.org/publicdomain/zero/1.0/) applies to the data made available in this article, unless otherwise stated. 
These guidelines confirm the appropriateness of initial antibiotic therapy as a crucial variable in septic patients $[1$, 5-9]. Among the major contributors of the increasing rates of inappropriate empiric antimicrobial treatment, the spread of antimicrobial resistance seems to be one of the most relevant [5, 6]. An update on sepsis epidemiology due to multi-drug resistant organisms (MDRO) and on its associated risk factors would be very helpful for clinicians to early detect patients requiring a broader antibiotic coverage.

Several experiences reported on risk factors for MDRO infections, enrolling heterogeneous patient populations. Some of them considered infections due to specific MDRO, mainly methicillin-resistant Staphylococcus aureus (MRSA) and extended-spectrum beta-lactamase (ESBL) producing Enterobacteriaceae [10-15], while others included patients with infection limited to one organ, such as pneumonia and urinary tract infections [16-20]. Finally, few other studies have been published on the impact of bacterial resistances in bloodstream infections, regardless the presence of sepsis [21-23]. No previous studies specifically evaluated prevalence, characteristics, and risk factors for MDRO in a specific sample of patients with sepsis.

The aim of this study was to assess prevalence, characteristics, risk factors, and outcomes of patients suffering of sepsis due to MDRO.

\section{Materials and methods}

\section{Study design and study patients}

This was an observational, retrospective study enrolling consecutive adult patients coming from the community and admitted to the Emergency Department (ED) of the IRCCS Fondazione Ca' Granda, Ospedale Maggiore Policlinico of Milan, Italy, with sepsis between January 2011 and December 2015. Patients $\geq 18$ years of age fitting sepsis criteria were included [4]. Patients admitted to the ED of the Policlinico Hospital coming from other hospitals were excluded. The study was approved by the ethical committee (262_2017bis) of the IRCCS Fondazione Ca' Granda, Ospedale Maggiore Policlinico of Milan, Italy, whereas informed consent was waived due to the retrospective and observational nature of the study according to the Italian law on observational studies.

\section{Data collection}

Demographics, comorbidities, risk factors for MDRO, Charlson Comorbidity Index, clinical, laboratory and microbiological findings on admission, site of infection, disease severity (organ dysfunction, septic shock, SOFA score) empiric antibiotic therapy, vasopressor use and invasive mechanical ventilation data were recorded $[24,25]$.

\section{Risk factors for MDRO}

The following risk factors for MDRO were recorded: nursing home or extended care facility residency, hospitalization for $\geq 2$ days in the preceding 90 days, antimicrobial therapy in the preceding 90 days, home infusion therapy (including antibiotics), home wound care, indwelling bladder catheter, indwelling intravascular devices, chronic renal failure, chronic dialysis at least during the prior 30 days, day hospital attendance for infusion therapy or blood transfusions, mild, moderate and severe immunodepression [26].

\section{Study outcomes and definitions}

The primary study outcome was in-hospital mortality. Secondary study outcome was length of hospital stay (LOS).

Sepsis and septic shock were defined according to the Third International Consensus Definitions for Sepsis and Septic Shock [4]. Sepsis was defined as life-threatening organ dysfunction caused by a dysregulated host response to infection. Organ dysfunction was identified as an acute change in total SOFA score $\geq 2$ points following the infection. Septic shock was defined as a subset of sepsis in which underlying circulatory and cellular metabolism abnormalities are severe enough to increase significantly mortality. This condition was identified with a clinical construct of sepsis with persisting hypotension requiring vasopressors to maintain mean arterial pressure (MAP) $\geq 65 \mathrm{mmHg}$ and having a serum lactate level $>2 \mathrm{mmol} / \mathrm{L}$ $(18 \mathrm{mg} / \mathrm{dL})$ despite adequate volume resuscitation.

Severe immunodepression was defined by the presence of at least one of the following medical conditions: active hematologic malignancy, transplantation, immunosuppressive therapy, chemotherapy and radiotherapy in the 30 days before the ED admission. Mild-to-moderate immunodepression was defined by the presence of at least one of the following medical conditions: chronic systemic steroid therapy (prednisone $\geq 25 \mathrm{mg}$ daily), active solid malignancy, splenectomy, and autoimmune disease.

In-hospital mortality was defined as all-cause mortality occurring during hospitalization. LOS was calculated as the number of days from the date of hospital admission to the date of discharge.

\section{Microbiological data and empiric antibiotic therapy}

Microbiological results performed within $48 \mathrm{~h}$ since hospital admission were recorded, including blood, sputum, tracheobronchial aspirate, urine, wound, and mucosal swab cultures, as well as Legionella pneumophila and Streptococcus pneumoniae urinary antigens. Species identification and antimicrobial susceptibility testing were performed using an automated system (Vitek $2^{\circ}$; BioMérieux); susceptibility break-points were based on Anti-microbial Susceptibility Testing (EUCAST) guidelines. [EUCAST breakpoint table version 1.2 to table version 5.0]. 
MRSA, Pseudomonas aeruginosa resistant to three classes of antibiotics among antipseudomonal penicillins, antipseudomonal cephalosporins, carbapenems, quinolones, and aminoglycosides, vancomycin-resistant Enterococcus, Acinetobacter baumanii, ESBL producing Enterobacteriaceae, carbapenemase-producing Klebsiella pneumoniae, and other pathogens with acquired non-susceptibility to at least one agent in three or more antimicrobials categories were considered as MDR bacteria [27].

Empiric antibiotic therapy administered in the ED after diagnosis of sepsis and septic shock was recorded, together with its appropriateness according to the antibiotic susceptibility of the isolated pathogen and the agreement with local guideline (see Additional file 1: Table S1).

\section{Statistical analysis}

An ad hoc electronic form was used to collect all demographic, epidemiological, clinical, and microbiological variables. Qualitative and quantitative data were summarized with absolute and relative (percentage) frequencies and medians (interquartile ranges, IQR) according to their non-parametric distribution, respectively. Statistical differences of qualitative and quantitative variables were assessed with chi-squared or Fisher exact, when appropriate, and Mann-Whitney tests, respectively. Logistic regression analyses were carried out to assess the relationship between MDRO or ESBL+ infection and the collected covariates. A two-tailed $p$ less than 0.05 was considered statistically significant. The statistical software STATA 14 (StataCorp LP, Lakeway Drive, College Station, USA) was used to perform all statistical computations.

\section{Results}

\section{Study population}

A total of 663 consecutive patients with sepsis were enrolled during the study period (56.6\% males, median [IQR] age: 80 [71-87] years). The final study population consisted of 518 patients $(78.1 \%$ of the total enrolled) who underwent at least one bacteriological test within the first $24 \mathrm{~h}$ after hospitalization.

Demographics, comorbidities, risk factors for MDRO, clinical, and laboratory findings on admission, site of infection, disease severity, therapy prescribed within $24 \mathrm{~h}$ after admission are summarized in Table 1: lung (59.9\%) and urinary tract (36.4\%) were the most common sites of infection. A total of 146 (28.2\%) patients had septic shock.

Three hundred ninety-seven patients $(76.6 \%)$ had at least one risk factor for MDRO: hospitalization in the previous 3 months (28.4\%), day hospital attendance (19.3\%), severe immunodepression (18.9\%), and antibiotic therapy in the last 90 days $(15.5 \%)$ were the most frequent risk factors for MDRO.
Prevalence and characteristics of patients with sepsis due to MDRO and ESBL+ bacteria

Cultures were performed on blood $(n=446,86.1 \%)$ and sputum $(n=25,4.8 \%)$ samples, tracheobronchial aspirates $(n=27,5.2 \%)$, urine $(n=189,36 \%$ ) and other $(n=47$, 9.1\%) samples. Microbiological findings are summarized in Table 2. At least one pathogen was isolated in 305 patients (58.9\%) and, among them, 198 (44.5\%) had bacteremia.

At least one MDRO was isolated in 88 patients $(17 \%$ among the entire population and $29.1 \%$ among culture positive patients), with ESBL+ Enterobacteriaceae being the most prevalent isolates (50 patients, 9.7\%), including $43(8.3 \%)$ patients with ESBL+ E. coli and 7 (1.4\%) with ESBL+ K. pneumoniae. The second most prevalent MDR bacteria were MRSA (20 patients, 3.9\%).

Demographics, comorbidities, risk factors, clinical and laboratory findings on admission, site of infection, disease severity, appropriateness of empiric antibiotic therapy, vasopressor use and invasive mechanical ventilation of the study sample are reported in the online supplement according to the presence of MDRO (Additional file 1: Table S2) and ESBL+ bacteria (Additional file 1: Table S3).

\section{Independent risk factors associated to MDRO and ESBL+ infection in patients with sepsis}

After adjusting for several confounders, independent risk factors associated with the occurrence of sepsis due to MDRO and ESBL+ bacteria are reported in Tables 3 and 4. Significant independent risk factors for sepsis due to MDRO were septic shock (OR: 2.2; 95\% CI: 1.3-3.7, $p=$ 0.002 ) and hospitalization in the past 90 days (OR: 2.3 ; $95 \%$ CI: $1.3-4.1, p=0.003)$. Significant independent risk factors for sepsis due to ESBL+ bacteria were hospitalization in the past 90 days (OR: 2.1 ; 95\% CI: $1.2-3.9, p=0.02$ ) and stroke (OR: 2.1 ; 95\% CI: 1.0-4.1, $p=0.04$ ).

\section{Study outcomes}

In-hospital mortality was $25.7 \%(n=133)$. Among patients with septic shock 69 (47.3\%) died. Demographics, comorbidities, risk factors, clinical laboratory, and microbiological findings on admission, site of infection, disease severity, appropriateness of empiric antibiotic therapy, vasopressors use and invasive mechanical ventilation of patients who died versus those who survived are summarized in Table 5.

The median (IQR) LOS was 13 (8-21) days. Among patients with MDRO the median (IQR) LOS was 15 (922) days and in-hospital mortality was $40.2 \%$ (35 patients), while among those without MDRO infection LOS was $13(8-21)$ days $(p=0.36)$ and mortality was $23.1 \%(n=98)(p=0.001)$.

Among patients with ESBL+ infection the median (IQR) LOS was 15 (9-21) days and in-hospital mortality was 
Table 1 Study population. (518)

\begin{tabular}{|c|c|}
\hline \multicolumn{2}{|l|}{ Demographics characteristics } \\
\hline Female, $n(\%)$ & $220(42.5)$ \\
\hline Median (IQR) age, years & $80(71-87)$ \\
\hline \multicolumn{2}{|l|}{ Comorbidities, n (\%) } \\
\hline Median (IQR) Charlson comorbidity index & $6(5-8)$ \\
\hline Hypertension & $289(55.8)$ \\
\hline Diabetes mellitus & $124(23.9)$ \\
\hline Ischemic heart disease & $109(21.0)$ \\
\hline COPD & $114(22.0)$ \\
\hline Stroke & $83(16.0)$ \\
\hline Dementia & $79(15.3)$ \\
\hline Chronic heart failure & $50(9.7)$ \\
\hline Chronic liver disease & $38(7.3)$ \\
\hline Peripheral vascular disease & $28(5.4)$ \\
\hline Hemiplegia & $21(4.1)$ \\
\hline Cirrhosis & $25(4.8)$ \\
\hline \multicolumn{2}{|l|}{ Risk factors for MDR pathogens, $n$ (\%) } \\
\hline $\begin{array}{l}\text { Patients with at least one risk factor for } \\
\text { MDR pathogens }\end{array}$ & $397(76.6)$ \\
\hline Hospitalization in the past 90 days & $147(28.4)$ \\
\hline Median (IQR) LOS & $13(8-21)$ \\
\hline Day hospital attendance in the past 90 days & $100(19.3)$ \\
\hline Antibiotic therapy in the past 90 days & $80(15.5)$ \\
\hline Severe immunosuppression & $98(18.9)$ \\
\hline Mild /moderate immunosuppression & $83(16.0)$ \\
\hline Solid cancer & $73(14.1)$ \\
\hline Chronic steroid therapy & $68(13.1)$ \\
\hline Haematological malignancy & $45(8.7)$ \\
\hline Chemotherapy & $28(5.4)$ \\
\hline AIDS & $3(0.6)$ \\
\hline Chronic renal failure & $96(18.5)$ \\
\hline Dialysis & $16(3.1)$ \\
\hline Home wound care/infusion therapy & $82(15.8)$ \\
\hline Indwelling bladder catheter & $70(13.5)$ \\
\hline Nursing home or LTCF residency & $45(8.7)$ \\
\hline Indwelling intravascular catheters & $31(6.0)$ \\
\hline \multicolumn{2}{|l|}{ Clinical findings } \\
\hline Median (IQR) body temperature, ${ }^{\circ} \mathrm{C}$ & $38.0(37.1-38.7)$ \\
\hline Median (IQR) systolic blood pressure, $\mathrm{mmHg}$ & $110(90-135)$ \\
\hline Median (IQR) diastolic blood pressure, $\mathrm{mmHg}$ & $60(50-70)$ \\
\hline Median (IQR) mean blood pressure, $\mathrm{mmHg}$ & $77(63-92)$ \\
\hline Median (IQR) heart rate, bpm & $102(88-120)$ \\
\hline Median (IQR) oxygen saturation, \% & $95(91-97)$ \\
\hline Median (IQR) respiratory rate, bpm & $22(18-30)$ \\
\hline Median (IQR) shock index & $0.9(0.7-1.2)$ \\
\hline
\end{tabular}

Table 1 Study population. (518) (Continued)

\begin{tabular}{|c|c|}
\hline \multicolumn{2}{|l|}{ Laboratory findings } \\
\hline Median (IQR) arterial pH & $7.5(7.4-7.5)$ \\
\hline Median (IQR) $\mathrm{PaCO}_{2}, \mathrm{mmHg}$ & $30(25-35)$ \\
\hline Median (IQR) $\mathrm{PaO}_{2}, \mathrm{mmHg}$ & $65(55-77)$ \\
\hline Median (IQR) $\mathrm{HCO}_{3}^{-} \mathrm{mEq} / \mathrm{L}$ & $21.8(18.0-24.6)$ \\
\hline Median (IQR) $\mathrm{PaO}_{2} / \mathrm{FiO}_{2}$ ratio & $276(229-333)$ \\
\hline Median (IQR) lactate, $\mathrm{mEq} / \mathrm{L}$ & $2.9(2.1-4.3)$ \\
\hline Median (IQR) white blood cells, cell/L $L^{-1}$ & $12.1(7.3-17.9)$ \\
\hline Median (IQR) platelets, cell/L $L^{-1}$ & $190.0(131.0-258.5)$ \\
\hline Mean (SD) haemoglobin, g/dL & $12.3(2.3)$ \\
\hline Median (IQR) glucose, mg/dL & $141(110-192)$ \\
\hline Median (IQR) urea, mg/dL & $65(46-97)$ \\
\hline Median (IQR) creatinine, $\mathrm{mg} / \mathrm{dL}$ & $1.6(1.2-2.4)$ \\
\hline Median (IQR) C-reactive protein, g/dL & $11.4(4.5-22.7)$ \\
\hline Median (IQR) aspartate aminotransferase U/I & $28(20-50)$ \\
\hline Median (IQR) alanine aminotransferase U/I & $21(13-39)$ \\
\hline Median (IQR) lactate dehydrogenase & $327(222-457)$ \\
\hline Median (IQR) total bilirubin, $\mathrm{mg} / \mathrm{dL}$ & $0.8(0.5-1.6)$ \\
\hline Median (IQR) INR & $1.3(1.2-1.5)$ \\
\hline \multicolumn{2}{|l|}{ Site of primary infection, $n$ (\%) } \\
\hline Lung & $273(59.9)$ \\
\hline Urinary tract & $166(36.4)$ \\
\hline Abdomen & $59(12.9)$ \\
\hline Skin and soft tissue & $31(6.8)$ \\
\hline Central nervous system & $9(2.0)$ \\
\hline Bone and joints & $4(0.9)$ \\
\hline More than one site & $82(15.8)$ \\
\hline Unknown origin & $62(12.0)$ \\
\hline \multicolumn{2}{|l|}{ MOF, n (\%) } \\
\hline Metabolic dysfunction & $359(75.6)$ \\
\hline Renal failure & $223(43.6)$ \\
\hline Hemodynamic failure & $200(39.0)$ \\
\hline Cognitive impairment & $158(32.9)$ \\
\hline Shock & $146(28.2)$ \\
\hline Respiratory failure & $94(18.4)$ \\
\hline Liver failure & $67(13.9)$ \\
\hline Coagulation dysfunction & $56(12.1)$ \\
\hline Haematological dysfunction & $51(9.9)$ \\
\hline \multicolumn{2}{|l|}{ Antibiotics, $n$ (\%) } \\
\hline Azithromycin & $40(5.5)$ \\
\hline Piperacillin/Tazobactam & $188(25.9)$ \\
\hline Ceftriaxone & $164(22.6)$ \\
\hline Levofloxacin & $111(15.3)$ \\
\hline Imipenem & $66(9.1)$ \\
\hline Vancomycin & $51(7.0)$ \\
\hline
\end{tabular}


Table 1 Study population. (518) (Continued)

\begin{tabular}{ll}
\hline Ciprofloxacin & $28(3.9)$ \\
Amoxicillin/Clavulanate & $22(3.0)$ \\
Metronidazole & $16(2.2)$ \\
Meropenem & $5(0.7)$ \\
Ampicillin & $7(1.0)$ \\
Amikacin & $7(1.0)$ \\
Ceftazidime & $5(0.7)$ \\
Others & $16(2.2)$ \\
Appropriate empiric antibiotic therapy according to & $273(58.3)$ \\
local guidelines & $155(66.8)$ \\
Appropriate empiric antibiotic therapy according to & \\
antibiotic susceptibility of the isolated pathogen & $84(16.2)$ \\
Use of vasopressors & $8(2.5)$ \\
Mechanical ventilation &
\end{tabular}

$n$ number, IQR interquartile range, COPD chronic obstructive pulmonary disease, AIDS Acquired immune deficiency syndrome; LTCF long term care facility, INR International normalized ratio; MOF: multi organ failure (other than primary site of infection)

$32 \%(n=16)$, whereas among those without ESBL+ infection median (IQR) LOS was $13(8-22)$ days $(p=0.73)$ and in-hospital mortality was $25.3 \%(n=117)(p=0.27)$.

\section{Risk factors for mortality in patients with sepsis}

After adjusting for several confounders, including antibiotic therapy, vasopressor exposure and ventilatory treatment, independent risk factors associated with in-hospital mortality in patients with sepsis were: coagulation dysfunction (OR: 3.2; 95\% CI: $1.1-8.8, p=0.03$ ), septic shock (OR: 3.2; 95\% CI: 1.5-7.0, $p=0.003$ ), and isolation of a MDR pathogen (OR: 4.6; 95\% CI: 2.0-10.6, $p<0.001$ ) (Table 6).

\section{Discussion}

The present study shows that more than three quarters of patients admitted to the hospital from the community for sepsis have at least one risk factor for MDRO, while in $17 \%$ of patients a MDRO is isolated. Among those, ESBL+ Enterobacteriaceae are the most prevalent ones (9.7\%). Hospitalization in the previous 90 days and the presence of septic shock are the two independent risk factors associated with MDRO in patients with sepsis, whereas hospitalization in the previous 90 days and stroke are independently associated with infection caused by ESBL producer Enterobacteraceae.

Our study is in line with previously published data in terms of frequency of different sites of infection (lung being the first followed by urinary tract), most frequent organs involved in multi-organ failure, percentage of patients with septic shock and mortality rate [28, 29]. The prevalence of MDRO in our study is slightly higher than those previously reported in literature, mainly
Table 2 Microbiological findings

\begin{tabular}{|c|c|}
\hline \multicolumn{2}{|l|}{ Microbiological, $n$ (\%) } \\
\hline Patients with isolated microorganism & $305(58.9)$ \\
\hline Patients with at least one MDR organism & $88(17.0)$ \\
\hline Patients with at least one ESBL organism & $50(9.7)$ \\
\hline E. coli ESBL + & $43(8.3)$ \\
\hline Methicillin-resistant S. aureus & $20(3.9)$ \\
\hline Proteus spp MDR + & $5(1)$ \\
\hline K. pneumoniae ESBL + & $7(1.4)$ \\
\hline K. pneumomiae carbapenemase producer & $6(1.2)$ \\
\hline P. aeruginosa MDR+ & $4(0.8)$ \\
\hline Enterococcus spp MDR+ & $2(0.4)$ \\
\hline Enterobacter spp MDR + & $2(0.4)$ \\
\hline Stenotrophomonas maltophilia MDR+ & $1(0.2)$ \\
\hline E. coli ESBL - & $77(14.9)$ \\
\hline Methicillin-sensible S. aureus & $24(4.6)$ \\
\hline S. pneumoniae & $24(4.6)$ \\
\hline K. pneumoniae ESBL- & $17(3.3)$ \\
\hline P. aeruginosa MDR- & $25(4.8)$ \\
\hline Candida spp & $12(2.3)$ \\
\hline Enterococcus spp MDR- & $10(1.9)$ \\
\hline Proteus spp MDR-) & $9(1.7)$ \\
\hline Enterobacter spp MDR- & $5(1)$ \\
\hline N. meningitides & $3(0.6)$ \\
\hline Bacteroides spp & $1(0.2)$ \\
\hline Providencia spp & $2(0.4)$ \\
\hline Stenotrophomonas maltophilia MDR- & $3(0.6)$ \\
\hline C. difficile & $4(0.8)$ \\
\hline Aspergillus spp & $2(0.4)$ \\
\hline Acinetobacter baumanii & $1(0.2)$ \\
\hline Salmonella group B & $2(0.4)$ \\
\hline H. influenzae & $1(0.2)$ \\
\hline Acinetobacter iwoffii & $1(0.2)$ \\
\hline Propiniobacterium & $1(0.2)$ \\
\hline Serratia spp & $2(0.4)$ \\
\hline Polymicrobial infection & $29(5.6)$ \\
\hline
\end{tabular}

$n$ number, ESBL extended spectrum beta lactamase, MDR multi-drug resistant, spp species

because of the characteristics of our study sample characterized by elderly patients with several comorbidities and a long history of medicalization [5, 30, 31]. We found a discrepancy between the frequency of risk factors for MDRO and the prevalence of cultures positive for MDRO. We could speculate that not all risk factors for MDRO should be equally weighted and share the same impact on guiding empiric antibiotic therapy in sepsis. 
Table 3 Logistic regression analysis to assess the relationship between MDR infection and demographic, epidemiological, clinical, and laboratory variables. (518)

\begin{tabular}{|c|c|c|c|c|}
\hline \multirow[t]{2}{*}{ Variables } & \multicolumn{2}{|c|}{ Univariate analysis } & \multicolumn{2}{|c|}{ Multivariate analysis } \\
\hline & $\overline{\mathrm{OR}}(95 \% \mathrm{Cl})$ & $p$ & $\overline{\mathrm{OR}}(95 \% \mathrm{Cl})$ & $p$ \\
\hline Female & $1.2(0.8-1.9)$ & 0.39 & $1.2(0.7-2.0)$ & 0.42 \\
\hline Age & $1.0(1.0-1.0)$ & 0.62 & $1.0(1.0-2.0)$ & 0.93 \\
\hline Septic shock & $2.1(1.3-3.4)$ & 0.002 & $2.2(1.3-3.7)$ & 0.002 \\
\hline Antibiotic therapy in the past 90 days & $1.7(1.1-3.3)$ & 0.03 & $1.0(0.5-2.0)$ & 1.0 \\
\hline Hospitalization in the past 90 days & $3.2(2.0-5.1)$ & $<0.0001$ & $2.3(1.3-4.1)$ & 0.003 \\
\hline Indwelling bladder catheter & $2.2(1.3-4.0)$ & 0.006 & $1.9(0.9-3.9)$ & 0.11 \\
\hline Home wound care/infusion therapy & $2.1(1.2-3.6)$ & 0.01 & $1.4(0.7-2.8)$ & 0.39 \\
\hline Chronic heart failure & $2.1(1.1-4.0)$ & 0.03 & $1.7(0.8-3.6)$ & 0.14 \\
\hline Peripheral vascular disease & $0.8(0.3-2.4)$ & 0.70 & & \\
\hline Stroke & $2.0(1.2-3.5)$ & 0.01 & $1.8(0.9-3.3)$ & 0.08 \\
\hline Dementia & $1.9(1.1-3.3)$ & 0.03 & $1.6(0.8-3.0)$ & 0.17 \\
\hline Haematological malignancy & $2.2(1.1-4.3)$ & 0.03 & $1.6(0.7-3.6)$ & 0.28 \\
\hline Chronic steroid therapy & $2.1(1.2-3.9)$ & 0.01 & $1.6(0.8-3.2)$ & 0.19 \\
\hline
\end{tabular}

Among healthcare-related risk factors, hospitalization in the previous 90 days is the strongest independent variable associated with MDRO-related sepsis. The increasing prevalence of MDRO within the hospital wards, due to an extensive antibiotic use and transmission between healthcare workers and patients, might explain this finding, as previously suggested in published manuscripts $[15,19,21,26,32]$. Also, septic shock is a risk factor for sepsis caused by MDRO, although some could argue that septic shock is a marker of disease severity and should not be considered a risk factor itself. As previously reported, markers of disease severity were included as risk factors for MDRO mainly because of the impact that this finding might have in the clinical management. Our finding on septic shock as independent risk factor for MDRO clearly identifies a subgroup of more fragile patients who might deserve a broad-spectrum empiric antibiotic course based on their disease severity and risk of organ failure. In light of the high prevalence of
MDRO we found and the high mortality rate of patients with septic shock, an antibiotic prescription for MDRO should be considered in shocked patients, especially if additional risk factors (e.g., previous hospitalization) are concomitant.

Among all MDRO, ESBL producer Enterobacteriaceae seems to be the most prevalent (9.7\%), with ESBL producing $E$. coli and $K$. pneumoniae being $35 \%$ of all $E$. coli and $K$. pneumoniae isolated. These data are similar to those reported in the scientific literature: frequency of sepsis due to gram negative bacteria (GNB) is increasing worldwide and $E$. coli is the most frequent GNB found in septic patients admitted from the community [3336]. The rate of ESBL production among Enterobacteriaceae varies from country to country but it is increasing through all Europe, with Italy having one of the highest prevalence [31]. We specifically identified that hospitalization in the previous 90 days is a specific risk factor for ESBL Enterobacteriaceae, showing the

Table 4 Logistic regression analysis to assess the relationship between ESBL infection and demographic, epidemiological, clinical, and laboratory variables. (518)

\begin{tabular}{|c|c|c|c|c|}
\hline \multirow[t]{2}{*}{ Variables } & \multicolumn{2}{|c|}{ Univariate analysis } & \multicolumn{2}{|c|}{ Multivariate analysis } \\
\hline & OR $(95 \% \mathrm{Cl})$ & $p$ & OR $(95 \% \mathrm{Cl})$ & $p$ \\
\hline Female & $1.0(0.5-1.8)$ & 0.94 & $1.0(0.5-1.8)$ & 0.87 \\
\hline Age & $1.0(1.0-1.1)$ & 0.10 & $1.0(1.0-1.0)$ & 0.50 \\
\hline Hospitalization in the past 90 days & $2.4(1.3-4.3)$ & 0.004 & $2.1(1.2-3.9)$ & 0.02 \\
\hline Indwelling bladder catheter & $2.5(1.3-5.1)$ & 0.008 & $2.0(0.9-4.1)$ & 0.08 \\
\hline Chronic heart failure & $2.3(1.0-5.0)$ & 0.04 & $1.8(0.8-4.1)$ & 0.18 \\
\hline Stroke & $2.5(1.3-4.9)$ & 0.006 & $2.1(1.0-4.1)$ & 0.04 \\
\hline Dementia & $2.4(1.2-4.7)$ & 0.01 & $2.0(1.0-4.0)$ & 0.06 \\
\hline
\end{tabular}


Table 5 Study population according to in-hospital mortality. (518)

\begin{tabular}{|c|c|c|c|}
\hline Variable & Survivors & Death & $p$ \\
\hline Hospital mortality, n (\%) & $378(74.0)$ & $133(25.7)$ & - \\
\hline \multicolumn{4}{|l|}{ Demographics characteristics } \\
\hline Female, $n(\%)$ & $158(41.8)$ & $59(44.4)$ & 0.61 \\
\hline Median (IQR) age & $78(69-85)$ & $81(75-87)$ & 0.01 \\
\hline \multicolumn{4}{|l|}{ Comorbidities, n (\%) } \\
\hline COPD & $85(22.5)$ & $28(21.1)$ & 0.73 \\
\hline Diabetes mellitus & $99(26.2)$ & $23(17.3)$ & 0.04 \\
\hline Hypertension & $211(55.8)$ & $75(56.4)$ & 0.91 \\
\hline Ischemic heart disease & $73(19.3)$ & $36(27.1)$ & 0.06 \\
\hline Chronic heart failure & $35(9.3)$ & $15(11.3)$ & 0.50 \\
\hline Peripheral vascular disease & $14(3.7)$ & $14(10.5)$ & 0.003 \\
\hline Stroke & $54(14.3)$ & $27(20.3)$ & 0.10 \\
\hline Hemiplegia & $14(3.7)$ & $7(5.3)$ & 0.44 \\
\hline Dementia & $54(14.3)$ & $24(18.1)$ & 0.30 \\
\hline Chronic liver disease & $27(7.1)$ & $11(8.3)$ & 0.67 \\
\hline Cirrhosis & $16(4.2)$ & $8(6.0)$ & 0.40 \\
\hline Chronic renal failure & $64(16.9)$ & $31(23.3)$ & 0.10 \\
\hline Active dialysis & $12(3.2)$ & $4(3.0)$ & 1.0 \\
\hline Solid cancer & $53(14.0)$ & $20(15.0)$ & 0.77 \\
\hline Haematological malignancy & $28(7.4)$ & $16(12.0)$ & 0.10 \\
\hline AIDS & $2(0.5)$ & $1(0.8)$ & 1.0 \\
\hline Chemotherapy & $19(5.0)$ & $9(6.8)$ & 0.45 \\
\hline Severe immunosuppression & $62(16.4)$ & 34 (25.6) & 0.02 \\
\hline Mild/moderate immunosuppression & $61(16.1)$ & $22(16.5)$ & 0.91 \\
\hline Chronic steroid therapy & $46(12.2)$ & $22(16.5)$ & 0.20 \\
\hline Median (IQR) Charlson comorbidity index & $6(4-8)$ & $7(5-9)$ & 0.001 \\
\hline \multicolumn{4}{|l|}{ Risk factors, $n$ (\%) } \\
\hline LTCF & $27(7.1)$ & $18(13.5)$ & 0.03 \\
\hline Antibiotic therapy in the past 90 days & $50(13.3)$ & $30(22.9)$ & 0.009 \\
\hline Hospitalization in the past 90 days & $91(24.1)$ & $55(41.4)$ & $<0.0001$ \\
\hline Home wound care/infusion therapy & $56(14.8)$ & $25(18.8)$ & 0.28 \\
\hline Day hospital attendance & $73(19.3)$ & $25(18.8)$ & 0.90 \\
\hline Indwelling bladder catheter & $49(12.9)$ & $20(15.0)$ & 0.55 \\
\hline Indwelling intravascular catheters & $24(6.4)$ & $7(5.3)$ & 0.65 \\
\hline \multicolumn{4}{|l|}{ Clinical findings } \\
\hline Median (IQR) body temperature, ${ }^{\circ} \mathrm{C}$ & $38.0(37.2-38.8)$ & $37.6(36.6-38.5)$ & 0.03 \\
\hline Median (IQR) systolic blood pressure, $\mathrm{mmHg}$ & $113(90-140)$ & $99(80-120)$ & 0.0001 \\
\hline Median (IQR) diastolic blood pressure, $\mathrm{mmHg}$ & $60(50-73)$ & $55(46-68)$ & 0.0006 \\
\hline Median (IQR) mean blood pressure, $\mathrm{mmHg}$ & $78(63-93)$ & $70(60-83)$ & 0.0001 \\
\hline Median (IQR) heart rate, bpm & $102(87-120)$ & $103(88-120)$ & 0.99 \\
\hline Median (IQR) oxygen saturation, \% & $95(92-98)$ & $94(90-97)$ & 0.06 \\
\hline Median (IQR) respiratory rate, bpm & $22(18-28)$ & $28(18-35)$ & 0.008 \\
\hline Median (IQR) shock index & $0.9(0.7-1.2)$ & $1.0(0.8-1.3)$ & 0.002 \\
\hline
\end{tabular}

Laboratory findings 
Table 5 Study population according to in-hospital mortality. (518) (Continued)

\begin{tabular}{|c|c|c|c|}
\hline Variable & Survivors & Death & $p$ \\
\hline Median (IQR) arterial pH & $7.5(7.4-7.5)$ & $7.4(7.4-7.5)$ & 0.0004 \\
\hline Median (IQR) $\mathrm{PaCO}_{2}, \mathrm{mmHg}$ & $30.0(26.0-35.0)$ & $31.0(24.0-36.5-)$ & 0.80 \\
\hline Median (IQR) $\mathrm{PaO}_{2}, \mathrm{mmHg}$ & $65(55-76)$ & $67(55-82)$ & 0.27 \\
\hline Median (IQR) $\mathrm{HCO}_{3}-\mathrm{mEq} / \mathrm{L}$ & $22.0(18.3-25.0)$ & $20.7(15.4-24.0)$ & 0.009 \\
\hline Median (IQR) $\mathrm{PaO}_{2} / \mathrm{FiO}_{2}$ ratio & $281.0(233.0-333.0)$ & $271.5(222.0-335.5)$ & 0.88 \\
\hline Median (IQR) lactate, $\mathrm{mEq} / \mathrm{L}$ & $2.8(2.1-4.0)$ & $3.1(2.1-5.7)$ & 0.02 \\
\hline Median (IQR) white blood cells, cell/L-1 & $12.2(7.4-17.8)$ & $12.5(7.3-19.3)$ & 0.50 \\
\hline Median (IQR) platelet, cell/L $L^{-1}$ & $198.0(140.0-254.0)$ & $181.0(105.5-276.0)$ & 0.45 \\
\hline Mean (SD) haemoglobin, g/dL & $12.6(2.2)$ & $11.4(2.3)$ & $<0.0001$ \\
\hline Median (IQR) glucose, mg/dL & $144.5(113.0-198.0)$ & $126.5(100.5-185.0)$ & 0.004 \\
\hline Median (IQR) urea, mg/dL & $58(43-87)$ & $87(63-145)$ & $<0.0001$ \\
\hline Median (IQR) creatinine, mg/dL & $1.5(1.1-2.1)$ & $2.0(1.5-4.1)$ & $<0.0001$ \\
\hline Median (IQR) C-reactive protein, g/dL & $10.0(3.8-21.6)$ & $15.7(7.1-25.9)$ & 0.0006 \\
\hline Median (IQR) Aspartate aminotransferase & $28(20-46)$ & $33(20-65)$ & 0.05 \\
\hline Median (IQR) Alanine aminotransferase & $21(13-40)$ & $24(12-39)$ & 0.85 \\
\hline Median (IQR) total bilirubin, $\mathrm{mg} / \mathrm{dL}$ & $0.8(0.5-1.7)$ & $1.0(0.6-1.6)$ & 0.52 \\
\hline Median (IQR) INR & $1.3(1.1-1.5)$ & $1.3(1.2-1.7)$ & 0.40 \\
\hline \multicolumn{4}{|l|}{ Site of infection, $n(\%)$} \\
\hline Lung & $192(57.3)$ & $77(67.0)$ & 0.07 \\
\hline Urinary tract & $134(40.0)$ & $31(27.0)$ & 0.01 \\
\hline Central nervous system & $6(1.8)$ & $2(1.7)$ & 1.0 \\
\hline Abdomen & $43(12.8)$ & $16(13.9)$ & 0.77 \\
\hline Skin and soft tissue) & $18(5.4)$ & $13(11.3)$ & 0.03 \\
\hline Bone and joints & $3(0.9)$ & $1(0.9)$ & 1.0 \\
\hline Multiple origin & $58(15.3)$ & $24(18.1)$ & 0.47 \\
\hline Unknown origin & $43(11.4)$ & $18(13.5)$ & 0.51 \\
\hline \multicolumn{4}{|l|}{ Severity of disease, $n$ (\%) } \\
\hline Hemodynamic failure & $136(36.3)$ & $64(48.9)$ & 0.01 \\
\hline Respiratory failure & $71(19.0)$ & $23(17.6)$ & 0.71 \\
\hline Renal failure) & $153(41.1)$ & $68(51.5)$ & 0.04 \\
\hline Liver failure & $44(12.6)$ & $23(18.1)$ & 0.12 \\
\hline Cognitive impairment & $106(29.9)$ & $49(40.8)$ & 0.03 \\
\hline Haematological dysfunction & $34(9.0)$ & $15(11.5)$ & 0.42 \\
\hline Coagulation dysfunction & $33(9.9)$ & $22(18.0)$ & 0.02 \\
\hline Metabolic dysfunction & $261(74.8)$ & $94(78.3)$ & 0.43 \\
\hline Shock & $75(19.8)$ & $69(51.9)$ & $<0.0001$ \\
\hline \multicolumn{4}{|l|}{ Microbiological findings, $n$ (\%) } \\
\hline Blood cultures performed in the first $48 \mathrm{~h}$ & $326(86.2)$ & $114(85.7)$ & 0.88 \\
\hline Bacteremia & $148(45.4)$ & $48(42.1)$ & 0.54 \\
\hline Cultures & () & ) & \\
\hline Culture positive & $224(59.3)$ & $77(57.9)$ & 0.78 \\
\hline Polymicrobial infection & $16(7.1)$ & $13(16.7)$ & 0.01 \\
\hline MDR pathogen isolated & $52(13.8)$ & $35(26.3)$ & 0.001 \\
\hline ESBL producer pathogen isolated & $33(8.7)$ & $16(12.0)$ & 0.27 \\
\hline
\end{tabular}


Table 5 Study population according to in-hospital mortality. (518) (Continued)

\begin{tabular}{llll}
\hline Variable & Survivors & Death & $p$ \\
\hline \multicolumn{1}{c}{ MRSA isolated } & $6(1.6)$ & $14(10.5)$ & $77(61.6)$ \\
Appropriate empiric antibiotic therapy according to local guidelines & $190(56.6)$ & $56(37,1 \%)$ & 0.33 \\
$\begin{array}{l}\text { Appropriate empiric antibiotic therapy according to antibiotic } \\
\text { susceptibility of the isolated pathogen }\end{array}$ & $118(71,1 \%)$ & $35(26.3)$ & 0,058 \\
Use of vasopressors & $49(13.0)$ & $4(5.3)$ & 0.001
\end{tabular}

$n$ number, IQR interquartile range, COPD chronic obstructive pulmonary disease, AIDS Acquired immune deficiency syndrome, LTCF long term care facility, INR International normalized ratio, MOF multi organ failure (other than primary site of infection)

important role played by the contact with health care setting, and suggesting the necessity of administering carbapenems empirically in septic patients with this risk factor. The other risk factor associated with ESBL+ bacteria is a positive history of stroke which could be explained in light of the prolonged hospitalization, nursing home residency or use of indwelling invasive devices (e.g., nasogastric tube, gastrostomy tube, bladder catheter). Considering the prevalence of ESBL Enterobacteriaceae and in case a MDRO infection is suspected (e.g., previous hospitalization), an empiric antibiotic therapy including carbapenems for ESBL+ pathogens could be considered, while waiting for culture results.
Sepsis due to MDRO is associated with higher mortality rates and the isolation of a MDRO is an independent risk factor for mortality. We know that patients presenting with MDRO infection have often a high number of comorbidities and a longer medical history, but also that MDRO infection and an inappropriate empirical antibiotic therapy are greatly correlated one to the other $[5,6]$. In some studies MDRO infection is an independent risk factor for mortality, whereas in others it is a risk factor for inappropriate antibiotic therapy being the last an independent risk factor for mortality $[5,15]$.

Our study has some limitations, including the retrospective nature and the single-center design. Our primary

Table 6 Logistic regression analysis to assess the relationship between hospital mortality and demographic, epidemiological, clinical, and laboratory variables. (518)

\begin{tabular}{|c|c|c|c|c|}
\hline \multirow[t]{2}{*}{ Variables } & \multicolumn{2}{|c|}{ Univariate analysis } & \multicolumn{2}{|c|}{ Multivariate analysis } \\
\hline & OR $(95 \% \mathrm{Cl})$ & p & OR $(95 \% \mathrm{Cl})$ & $p$ \\
\hline Female & $1.1(0.7-1.7)$ & 0.61 & $1.1(0.5-2.3)$ & 0.79 \\
\hline Age & $1.0(1.0-1.0)$ & 0.01 & $1.0(1.0-1.1)$ & 0.053 \\
\hline Septic shock & $4.4(2.9-6.7)$ & $<0.0001$ & $3.2(1.5-7.0)$ & 0.003 \\
\hline Nursing home & $2.0(1.1-3.8)$ & 0.03 & $0.4(0.1-1.4)$ & 0.14 \\
\hline Antibiotic therapy in the past 90 days & $1.9(1.2-3.2)$ & 0.01 & $1.1(0.4-3.0)$ & 0.90 \\
\hline Hospitalization in the past 90 days & $2.2(1.5-3.4)$ & $<0.0001$ & $1.1(0.4-2.7)$ & 0.85 \\
\hline Diabetes mellitus & $0.6(0.4-1.0)$ & 0.04 & $0.8(0.3-2.1)$ & 0.71 \\
\hline Peripheral vascular disease & $3.1(1.4-6.6)$ & 0.004 & $1.4(0.3-5.9)$ & 0.67 \\
\hline Severe immunosoppression & $1.8(1.1-2.8)$ & 0.02 & $1.9(0.8-4.9)$ & 0.17 \\
\hline Lung site & $1.5(1.0-2.4)$ & 0.07 & $1.7(0.7-4.0)$ & 0.21 \\
\hline Urinary tract site & $0.6(0.4-0.9)$ & 0.01 & $0.6(0.3-1.5)$ & 0.27 \\
\hline Skin and soft tissue site & $2.2(1.1-4.7)$ & 0.03 & $3.2(0.9-11.4)$ & 0.07 \\
\hline Renal failure & $1.5(1.0-2.3)$ & 0.04 & $1.5(0.7-3.1)$ & 0.26 \\
\hline Cognitive impairment & $1.6(1.1-2.5)$ & 0.03 & $1.5(0.7-3.0)$ & 0.30 \\
\hline Coagulation dysfunction & $2.0(1.1-3.6)$ & 0.02 & $3.2(1.1-8.8)$ & 0.03 \\
\hline SOFA & $1.3(1.2-1.4)$ & $<0.0001$ & & \\
\hline Quick SOFA & $1.5(1.1-2.1)$ & 0.008 & & \\
\hline MDR pathogen isolated & $2.2(1.4-3.6)$ & 0.001 & $4.6(2.0-10.6)$ & $<0.001$ \\
\hline Use of vasopressors & $2.4(1.5-3.9)$ & $<0.0001$ & & \\
\hline Polymicrobial infection & $2.6(1.2-5.7)$ & 0.02 & $2.4(0.7-7.7)$ & 0.15 \\
\hline
\end{tabular}


outcome was mortality due to all causes during hospitalization, while sepsis-related mortality and long term outcomes would have been additional and interesting primary outcomes. Finally, we found $41.7 \%$ of population who received an empiric antibiotic therapy not concordant with local guidelines. Our local guidelines suggest broad antimicrobial spectrum antibiotics in patients with a suspicion of MDRO infection according to a list of risk factors recorded from previously published literature. So far, no specific risk factors for single MDRO in septic patients were identified. For the first time, we showed hospitalization in the previous 90 days and stroke as independently associated with ESBL+ bacterial infection in sepsis. Finally, our results should be interpreted with caution and not be widely generalized, as different causative pathogens of sepsis, different rates of antibiotic resistances, as well as risk factors related to different healthcare organizations might be recognized worldwide.

The strength and novelty of our study lie on a specific analysis of all risk factors for MDRO in a large sample of consecutive patients coming from the community and admitted to the ED, during a 5-year period, with the diagnosis of sepsis according to Sepsis-3 definition [4]. Several studies evaluated risk factors for MDRO in either bacteremic patients or in those affected by single organ disease (e.g., pneumonia). Our study is the first one evaluating all risk factors for MDRO previously published in literature in patients with sepsis regardless the site of infection.

\section{Conclusion}

In conclusion, our finding of an isolation of a MDRO in $17 \%$ of patients with sepsis coming from the community advocates for a better recognition of possible risk factors for MDRO and especially for ESBL+ Enterobacteriaceae. Patients with sepsis who have been hospitalized in the previous 90 days and/or with a history of stroke might be ideal candidate for a broader empiric antibiotic therapy covering ESBL+ Enterobacteriaceae, while waiting for microbiological results.

\section{Additional file}

Additional file 1: Table S1. Local guidelines for empirical antibiotic therapy in sepsis and septic shock. Table S2. Characteristics of the study sample stratified by MDR bacterial infection. (518). Table S3. Characteristics of the study sample stratified by ESBL+ bacterial infection. (518). (DOCX 54 kb)

\section{Abbreviations}

AIDS: Acquired immune deficiency syndrome; COPD: Chronic obstructive pulmonary disease; ED: Emergency department; ESBL: Extended-spectrum beta-lactamases; GNB: Gram negative bacteria; ICU: Intensive care unit; INR: International normalized ratio; IQR: Interquartile ranges; LOS: Length of hospital stay; LTCF: Long term care facility; MDR: Multi-drug resistant; MDRO: Multi-drug resistant organisms; MOF: Multi organ failure; MRSA: Methicillin-resistant Staphylococcus aureus; SOFA: Sequential Organ Failure Assessment

\section{Acknowledgments}

We thank all clinicians in the Policlinico Hospital in Milan, Italy, for their cooperation and participation in the study.

Funding

No funding.

\section{Availability of data and materials}

The datasets used and/or analysed during the current study are available from the corresponding author on reasonable request.

\section{Authors' contributions}

NC, PB, SA and AB conceived of the study, and participated in its design and coordination and helped to draft the manuscript. GS and LS performed the statistical analysis. DS, EC, LL, DP, BV and VM participated to the acquisition and interpretation of data. All authors read and approved the final manuscript.

Ethics approval and consent to participate

The study was approved by the ethical committee (262_2017bis) of the IRCCS Fondazione Ca' Granda, Ospedale Maggiore Policlinico of Milan, Italy, whereas informed consent was waived due to the retrospective and observational nature of the study according to the Italian law on observational studies.

\section{Consent for publication}

Not applicable.

\section{Competing interests}

The authors declare that they have no competing interests. All authors have submitted the ICMJE Form for Disclosure of Potential Conflicts of Interests.

SA and GS are Associate Editors of Multidisciplinary Respiratory Medicine.

\section{Publisher's Note}

Springer Nature remains neutral with regard to jurisdictional claims in published maps and institutional affiliations.

\section{Author details}

${ }^{1}$ Department of Emergency Medicine, Fondazione IRCCS Cà Granda Ospedale Maggiore Policlinico, Milan, Italy. ${ }^{2}$ Fondazione IRCCS Ca' Granda Ospedale Maggiore Policlinico, Respiratory Unit and Cystic Fibrosis Adult Center, Via Francesco Sforza 35, 20122 Milan, Italy. ${ }^{3}$ Department of Pathophysiology and Transplantation, University of Milan, Milan, Italy. ${ }^{4}$ Clinical Epidemiology and Medical Statistics Unit, Department of Biomedical Sciences, Medical Education and Professional Development Unit, AOU Sassari, University of Sassari - Research, Sassari, Italy. ${ }^{5}$ Department of Emergency Medicine -ASST-Papa Giovanni XXIII, Bergamo, Italy. ${ }^{6}$ Acute Internal Medicine, Fondazione IRCCS Cà Granda Ospedale Maggiore Policlinico, Milan, Italy.

Received: 13 February 2019 Accepted: 29 April 2019

Published online: 05 July 2019

\section{References}

1. Rhodes A, Evans LE, Alhazzani W, Levy MM, Antonelli M, Ferrer R, et al. Surviving sepsis campaign. Intensive Care Med. 2017;43(3):304-77.

2. Fleischmann C, Thomas-Rueddel DO, Hartmann M, Hartog CS, Welte T, Heublein S, et al. Fallzahlen und sterblichkeitsraten von sepsis-patienten im krankenhaus. Dtsch Arztebl Int. 2016;113:159-66.

3. Arefian H, Heublein S, Scherag A, Brunkhorst FM, Younis MZ, Moerer O, et al. Hospital-related cost of sepsis: a systematic review. J Inf Secur. 2017;74: 107-17

4. Singer M, Deutschman CS, Seymour CW, Shankar-Hari M, Annane D, Bauer $M$, et al. The third international consensus definitions for sepsis and septic shock (Sepsis-3). JAMA. 2016;315:801-10.

5. Vazquez-Guillamet C, Scolari M, Zilberberg MD, Shorr AF, Micek ST, Kollef M. Using the number needed to treat to assess appropriate antimicrobial therapy as a determinant of outcome in severe sepsis and septic shock. Crit Care Med. 2014;42:1-8.

6. Zilberberg MD, Shorr AF, Micek ST, Vazquez-Guillamet C, Kollef MH. Multidrug resistance, inappropriate initial antibiotic therapy and mortality in gram-negative severe sepsis and septic shock: a retrospective cohort study. Crit Care. 2014;18:596. 
7. Ratzinger F, Eichbichler K, Schuardt M, Tsirkinidou I, Mitteregger D, Haslacher $\mathrm{H}$, et al. Sepsis in standard care: patients characteristics, effectiveness of antimicrobial therapy and patient outcome a cohort study. Infection. 2015:43:345-52.

8. Leibovici L, Shraga I, Drucker M, Konigsberger H, Samra Z, Pitlik SD. The benefit of appropriate empirical antibiotic treatment in patients with bloodstream infection. J Intern Med. 1998;244:379-86.

9. Leone M, Bourgoin A, Cambon S, Dubuc M, Albanèse J, Martin C. Empirical antimicrobial therapy of septic shock patients: adequacy and impact on the outcome. Crit Care Med. 2003:31:462-7.

10. Aliberti S, Reyes LF, Faverio P, Sotgiu G, Dore S, Rodriguez AH, et al. Global initiative for meticillin-resistant Staphylococcus aureus pneumonia (GLIMP): an international, observational cohort study. Lancet Infect Dis. 2016;3099:1-12.

11. McKinnell JA, Miller LG, Eells SJ, Cui E, Huang SS. A systematic literature review and meta-analysis of factors associated with methicillin-resistant Staphylococcus aureus colonization at time of hospital or intensive care unit admission. Infect Control Hosp Epidemiol. 2013;34:1077-86.

12. Harbarth S, Sax H, Fankhauser-Rodriguez C, Schrenzel J, Agostinho A, Pittet D. Evaluating the probability of previously unknown carriage of MRSA at hospital admission. Am J Med. 2006;119:15-23.

13. Tacconelli E, De Angelis G, Cataldo MA, Pozzi E, Cauda R. Does antibiotic exposure increase the risk of methicillin-resistant Staphylococcus aureus (MRSA) isolation? A systematic review and meta-analysis. J Antimicrob Chemother. 2008;61:26-38.

14. Tumbarello M, Trecarichi EM, Bassetti M, De Rosa FG, Spanu T, Di Meco E, et al. Identifying patients harboring extended-spectrum-beta-lactamaseproducing Enterobacteriaceae on hospital admission: derivation and validation of a scoring system. Antimicrob Agents Chemother. 2011;55: 3485-90.

15. Trecarichi EM, Cauda R, Tumbarello M. Bloodstream infections. Future Microbiol. 2012;7:1173-89.

16. Aliberti S, Di Pasquale M, Zanaboni AM, Cosentini R, Brambilla AM, Seghezzi $\mathrm{S}$, et al. Stratifying risk factors for multidrug-resistant pathogens in hospitalized patients coming from the community with pneumonia. Clin Infect Dis. 2012:54:470-8

17. Shorr AF, Zilberberg MD, Reichley R, Kan J, Hoban A, Hoffman J, et al. Validation of a clinical score for assessing the risk of resistant pathogens in patients with pneumonia presenting to the emergency department. Clin Infect Dis. 2012;54:193-8.

18. Shindo $Y$, Ito R, Kobayashi D, Ando M, Ichikawa M, Shiraki A, et al. Risk factors for drug-resistant pathogens in community-acquired and healthcareassociated pneumonia. Am J Respir Crit Care Med. 2013;188:985-95.

19. Sibila O, Rodrigo-Troyano A, Shindo Y, Aliberti S, Restrepo MI. Multidrugresistant pathogens in patients with pneumonia coming from the community. Curr Opin Pulm Med. 2016;22:219-26.

20. Faine BA, Harland KK, Porter B, Liang SY, Mohr N. A clinical decision rule identifies risk factors associated with antimicrobial-resistant urinary pathogens in the emergency department: a retrospective validation study Ann Pharmacother. 2015;49:649-55.

21. Health Friedman ND, Kaye KS, Stout JE, McGarry SA, Trivette SL, Briggs JP, et al. Health care-associated bloodstream infections in adults: a reason to change the accepted definition of community-acquired infections. Ann Intern Med. 2002;137:791-7.

22. Lim CJ, Cheng AC, Kong DCM, Peleg AY. Community-onset bloodstream infection with multidrug-resistant organisms : a matched case-control study. BMC Infect Dis. 2014;14:1-9.

23. Tacconelli E, Cataldo MA, De Angelis G, Cauda R. Risk scoring and bloodstream infections. Int J Antimicrob Agents. 2007;30:88-92.

24. Charlson ME, Pompei P, Ales KL, Mackenzie CR. A new method of classifying prognostic comorbidity in longitudinal studies: development and validation. J Chronic Dis. 1987:40:372-83.

25. Vincent J, Moreno R, Takala J, Willatts S, De Mendonça A, Bruining $\mathrm{H}$, et al. The SOFA (sepsis-related organ failure assessment) score to describe organ dysfunction/failure. On behalf of the Working Group on Sepsis-Related Problems of the European Society of Intensive Care Medicine. Intensive Care Med. 1996;22:707-10.

26. American Thoracic Society; Infectious Diseases Society of America. Guidelines for the management of adults with hospital-acquired, ventilatory-associated, and healthcare-associated pneumonia. Am J Respir Crit Care Med. 2005;171:388-416.
27. Magiorakos A, Srinivasan A, Carey RB, et al. Bacteria: an international expert proposal for interim standard definitions for acquired resistance. Microbiology. 2011;18:268-81.

28. Angus DC, van der Poll T. Severe sepsis and septic shock. N Engl J Med. 2013;369:840-51.

29. Mayr FB, Yende S, Angus DC. Epidemiology of severe sepsis. Virulence. 2014; 5:4-11.

30. Anderson DJ, Moehring RW, Sloane R, Schmader KE, Weber DJ, Fowler VG $\mathrm{Jr}$, et al. Bloodstream infections in community hospitals in the 21st century: a multicenter cohort study. PLoS One. 2014;9:1-10.

31. ECDC. Antimicrobial Resistance surveillance in Europe. 2015.

32. Marchaim D, Gottesman T, Schwartz O, Korem M, Maor Y, Rahav G, et al. National multicenter study of predictors and outcomes of bacteremia upon hospital admission caused by Enterobacteriaceae producing extendedspectrum beta-lactamases. Antimicrob Agents Chemother. 2010;54:5099104.

33. Marshall J, Anzueto A, Martin CD, Gomersall C. Characteristics of Total study group, vol. 302; 2013. p. 2323-9.

34. Luzzaro F, Ortisi G, Larosa M, Drago M, Brigante G, Gesu G. Prevalence and epidemiology of microbial pathogens causing bloodstream infections: results of the OASIS multicenter study. Diagn Microbiol Infect Dis. $2011 ; 69: 363-9$.

35. Rodríguez-Baño J, López-Prieto MD, Portillo MM, Retamar P, Natera C, Nuño E, et al. Epidemiology and clinical features of community-acquired, healthcare-associated and nosocomial bloodstream infections in tertiarycare and community hospitals. Clin Microbiol Infect. 2010;16:1408-13.

36. Kollef MH, Zilberberg MD, Shorr AF, Vo L, Schein J, Micek ST, et al. Epidemiology, microbiology and outcomes of bacteremia: a multicenter cohort study. J Inf Secur. 2011;62:130-5.

\section{Ready to submit your research? Choose BMC and benefit from:}

- fast, convenient online submission

- thorough peer review by experienced researchers in your field

- rapid publication on acceptance

- support for research data, including large and complex data types

- gold Open Access which fosters wider collaboration and increased citations

- maximum visibility for your research: over $100 \mathrm{M}$ website views per year

At $\mathrm{BMC}$, research is always in progress.

Learn more biomedcentral.com/submissions 